\section{Which visual acuity measurements define high-quality care for patients with neovascular age-related macular degeneration treated with ranibizumab?}

AH Ross', PHJ Donachie², A Sallam', IM Stratton², Q Mohamed', PH Scanlonn ${ }^{1,2}$, JN Kirkpatrick and RL Johnston'

\footnotetext{
'Ophthalmology

Department,

Gloucestershire Hospitals,

Cheltenham, UK
}

${ }^{2}$ Gloucestershire Retinal

Research Group,

Cheltenham General

Hospital, Cheltenham, UK

Correspondence:

RL Johnston,

Ophthalmology

Department, Cheltenham

General Hospital,

Cheltenham,

Gloucestershire

GL53 7AN, UK

Tel: +44 (0) 8454222529

Fax: + 44 (0) 2074875998

E-mail: rob.johnston@glos.

nhs.uk

Received: 2 May 2012

Accepted in revised form:

25 September 2012

Published online:

23 November 2012

\begin{abstract}
Purpose The purpose of this study is to define which visual acuity (VA) measurements are the best indicators of highquality care for patients receiving intravitreal ranibizumab for neovascular age-related macular degeneration (nAMD).

Methods Analysis of prospectively collected data recorded within an electronic medical record system on treatment-naive, firsteligible eyes with nAMD, treated with ranibizumab using an as-needed treatment regimen with a minimum follow-up of 1 year. Data collection included the following: age, gender, laterality, type of nAMD, VA, central $1 \mathrm{~mm}$ OCT retinal thickness, number of intravitreal injections, and number of follow-up assessments. Results Data were available on the firsttreated eye from 406 patients with at least 1 year follow-up; of these, 198 had data at 2 years. The mean baseline VA of 54.4 Early Treatment Diabetic Retinopathy Study letters improved to $\mathbf{5 8 . 5}$ letters at $\mathbf{1 2}$ months and to 56.8 letters at 24 months. The mean VA changes from baseline to 1 year were +6.5 , $+7.5,+1.7$, and -1.5 letters, respectively, for baseline VA categories of $23-35,36-55,56-70$, and $>70$ letters. Change in mean VA from the end of the loading phase to year 1 ranged from -2.9 to +1.4 letters for the different baseline VA categories. The mean number of injections were similar across baseline VA categories ranging from 5.7 to 6.0 injections in year 1 and from 3.3 to 3.8 in year 2 .
\end{abstract}

Conclusions This large, real-world series demonstrates that mean change in VA is largely a function of selection criteria and baseline VA. The quality of a service is therefore better judged by actual VA outcomes and maintenance of vision after the loading phase.

Eye (2013) 27, 56-64; doi:10.1038/eye.2012.225; published online 23 November 2012

Keywords: ranibizumab; visual acuity; agerelated macular degeneration; neovascular

Introduction

Age-related macular degeneration (AMD) is the leading cause of visual loss in the developed world in the adult population. ${ }^{1}$ The advent of anti-vascular endothelial growth factor (antiVEGF) drugs has revolutionised treatment for neovascular AMD (nAMD).

The landmark randomised controlled clinical trials, MARINA ${ }^{2}$ and $\mathrm{ANCHOR}^{3,4}$ defined the gold standard for visual acuity (VA) outcomes for selected patient populations with nAMD, which can be achieved with monthly injections for 24 months. MARINA (minimally classic/occult lesions) demonstrated a mean improvement of +7.2 letters on the Early Treatment Diabetic Retinopathy Study (ETDRS) chart in ranibizumab-treated eyes ( $0.5 \mathrm{mg}$ group) at 12 months and of +6.6 letters at 24 months. 
ANCHOR (predominantly classic lesions) demonstrated a gain of +11.3 letters in $0.5 \mathrm{mg}$ ranibizumab-treated eyes at 12 months $^{3}$ and of +10.7 letters at 24 months, compared with a mean decline of -9.8 letters in the control group of photodynamic therapy-treated eyes at 24 months. ${ }^{4}$

The monthly administration schedule used in the landmark trials when translated into clinical practice places a substantial burden on patients, retinal services, and entities that fund health care. Less frequent dosing regimens have therefore been investigated.

The PRONTO study, ${ }^{5}$ a small case series using an asneeded dosing regimen with intravitreal ranibizumab after an initial induction phase of three consecutive monthly injections, demonstrated comparable results to ANCHOR and MARINA, with a mean of 5.5 injections in the first year and 4.4 injections in the second year. This protocol has been widely adopted in an attempt to deliver the clinical outcome benefits seen in the landmark trials at lower cost.

There are few studies of clinical outcomes of treatment for $\mathrm{nAMD}$ with ranibizumab in the routine clinical setting. ${ }^{6-16}$

The aims of this paper are to establish VA outcomes and number of injections required each year for eyes with different baseline VA in a large cohort of treatment-naive patients in a real-world clinical setting. In addition, we wish to establish which measures of VA are the best measures of the quality of a service.

\section{Materials and methods}

\section{Study population}

Treatment-naive first-eligible eyes with nAMD and a presenting VA of 23 or more letters treated within a large public hospital serving a geographically defined area of the United Kingdom.

\section{Study design}

Data were prospectively collected in an electronic medical record system (EMR; Medisoft Ophthalmology, Leeds, UK).

Unlike in the landmark trials, eyes with a long duration of symptoms were included, as were eyes with some permanent structural changes at the fovea and eyes having VA of better than 70 ETDRS letters (6/12 Snellen equivalent) at baseline. Exclusion criteria for this study of NHS care included the following: prior treatment with ranibizumab or bevacizumab privately, and prior or concurrent photodynamic therapy, thermal laser therapy, or gas injections for nAMD, peripapillary lesions, extrafoveal lesions, or baseline VA of $<23$ ETDRS letters, the lower limit for NHS funding for ranibizumab. We also excluded patients with follow-up of less than 1 year.

Data collection for each patient included the following: age at presentation, gender, type of nAMD lesion, VA letter score at presentation and at every follow-up visit, OCT central $1 \mathrm{~mm}$ retinal thickness measurements at baseline and each follow-up assessment, the number of intravitreal injections, and follow-up examinations in each year of follow-up.

\section{Service design and treatment protocol}

The diagnosis of nAMD was confirmed by fundus fluorescein angiography before initiating treatment. Indocyanine green angiography was only available at one of the two main sites, and, therefore, eyes with idiopathic polypoidal choroidal vasculopathy or retinal angiomatous proliferation were not consistently identified and were included within the occult CNV category for analysis in this study. After a loading phase of three consecutive monthly injections, re-treatment with ranibizumab was performed if any of the following criteria was fulfilled at subsequent monthly assessments: $>20 \%$ increase in central $1 \mathrm{~mm}$ retinal thickness since last visit on OCT, presence or qualitative increase in the amount of intraretinal/subretinal fluid on OCT, or appearance of new macular haemorrhage on fundal examination with or without a decrease in VA. If the intraretinal fluid or subretinal fluid persisted despite numerous injections, then treatment was stopped but was restarted if there was a qualitative deterioration.

\section{Refraction and VA}

A subjective refraction was performed before the first injection and this refraction was used in trial frames for all subsequent VA measurements if it was different to the patient's glasses prescription. All VA values were recorded in ETDRS letter score notation using $4 \mathrm{~m}$ ETDRS charts at $2 \mathrm{~m}$.

\section{Statistical analysis}

Analysis was restricted to the first-eligible treated eye if both eyes were treated. VA groups were categorised as: 23-35, 36-55, 56-70, and > 70 letters at baseline, 1 , and 2 years. The end of years 1 and 2 were defined as data available at $12 \pm 1$ month and $24 \pm 1$ month, respectively, from the first injection. All analyses was performed using STATA version-11 (StataCorp, College Station, TX, USA). ${ }^{17}$ 


\section{Results}

\section{Study population and analytical samples}

Data on 700 eyes (629 patients) treated in the Gloucestershire Hospitals NHS Foundation Trust for nAMD, with their first anti-VEGF injection from December 2007 to May 2010, were anonymised and extracted from the EMR. Of these, 294 eyes (223 patients) did not meet the inclusion criteria.

The reasons for exclusion were: 160 eyes treated privately ( 88 with bevacizumab, 72 with ranibizumab), almost all before ranibizumab being funded by the NHS; 24 eyes had baseline best-corrected VA below 23 ETDRS letters; 15 eyes were treated for peripapillary lesions; 6 had received other prior or concurrent non-anti-VEGF treatments for nAMD in the presenting eye (4 photodynamic therapy, 1 thermal laser, 1 gas injection); in 4 eyes there was a trial of treatment with no intent to give the full loading course of injections; and 38 eyes because they were the second eligible treated eye. In addition, 47 eyes from 47 patients were excluded because of lack of 1 year follow-up data; 27 of these were permanently no longer attending the clinic by the end of year 1 (20 had died, 5 had left the area, and 2 had been discharged with VA consistently below the level eligible for NHS ranibizumab treatment $<23$ ETDRS letters), and 20 patients had no end of year 1 VA recorded. Baseline characteristics were similar between these 47 eyes and the eligible analysed cohort for gender, mean baseline OCT thickness, and nAMD diagnosis; however, these patients were slightly older and had a lower baseline VA in the affected eye.

Two years after the first injection of ranibizumab, $198 / 205(96.6 \%)$ patients who were potentially available for follow-up had a VA value recorded (5 were still under follow-up, but had no VA data recorded at that time point; 1 patient was discharged before 2 years, as they were deemed to have a stable scar; and 1 patient refused further treatment). Nineteen patients died during the second year of follow-up and were therefore not available for follow-up. A total of 178 patients had not reached 2 years after the first injection. This meant data was available on the first-treated eye from 406 patients with at least 1 year follow-up, and of these 198 had data at 2 years.

Figure 1 illustrates a flow diagram to describe the attrition of numbers over the 2 years.

\section{Study population and baseline characteristics}

In total, 137 patients were male (33.7\%) and the median age at the time of the first injection of ranibizumab was 82 years (range: $54-99$ years). The baseline characteristics are shown in Table 1.

The baseline mean VA was 54.4 ETDRS letters. Fiftyfour $(13.3 \%)$ patients had a baseline VA of 23-35 letters,

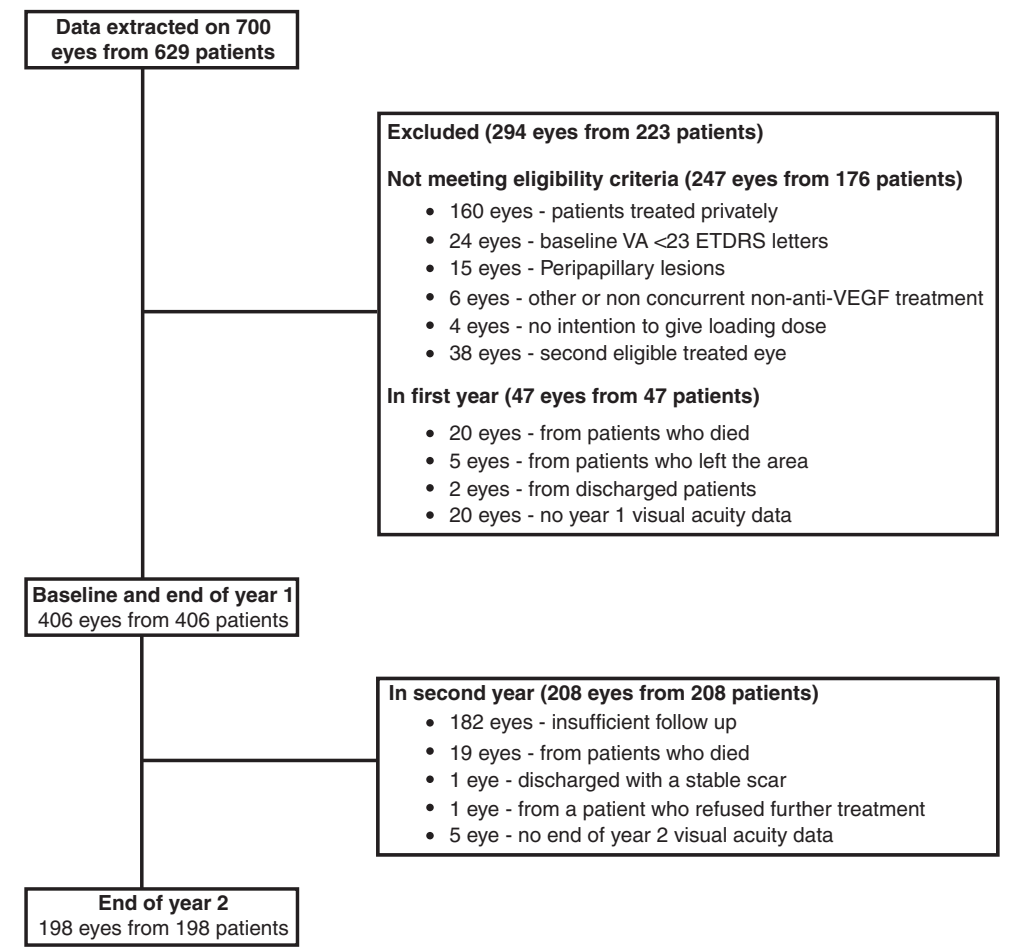

Figure 1 Flow diagram to describe the attrition of numbers over 2 years. 
Table 1 Baseline and demographic information for all eligible patients

\begin{tabular}{|c|c|c|c|}
\hline Variable (\% within gender) & Male $(\mathrm{N}=137)$ & Female $(\mathrm{N}=269)$ & Total $(\mathrm{N}=406)$ \\
\hline Left eyes & $62(45.3)$ & $133(49.4)$ & $195(48.0)$ \\
\hline Right eyes & $75(54.7)$ & $136(50.6)$ & $211(52.0)$ \\
\hline \multicolumn{4}{|l|}{ Age at first injection (years) } \\
\hline Median & 80.8 & 83.0 & 82.3 \\
\hline Interquartile range & $74.6-85.9$ & $77.8-86.9$ & $76.9-86.3$ \\
\hline Range & $56.8-94.3$ & $54.2-99.5$ & $54.2-99.5$ \\
\hline \multicolumn{4}{|l|}{ Fluorescein/indocyanine green angiogram subtypes } \\
\hline Minimally classic/occult no classic CNV & $92(67.2)$ & $196(72.9)$ & $288(70.9)$ \\
\hline Classic no occult/predominantly classic CNV & $44(32.1)$ & $69(25.7)$ & $113(27.8)$ \\
\hline FFA unassessable/not performed & $1(0.7)$ & $4(1.5)$ & $5(1.2)$ \\
\hline \multicolumn{4}{|l|}{ Baseline VA (number of ETDRS letters) } \\
\hline Mean & 53.8 & 54.8 & 54.4 \\
\hline SD & 12.9 & 14.9 & 14.2 \\
\hline \multicolumn{4}{|l|}{ VA category, $\mathrm{N}(\%)$} \\
\hline 23-35 ETDRS letters & $15(10.9)$ & 39 (14.5) & $54(13.3)$ \\
\hline 36-55 ETDRS letters & $60(43.8)$ & $84(31.2)$ & $144(35.5)$ \\
\hline 56-70 ETDRS letters & $52(38.0)$ & $110(40.9)$ & $162(39.9)$ \\
\hline >70 ETDRS letters & $10(7.3)$ & $36(13.4)$ & $46(11.3)$ \\
\hline \multicolumn{4}{|l|}{ Baseline OCT $(\mu \mathrm{m})$} \\
\hline Mean & 359.9 & 350.0 & 353.1 \\
\hline SD & 101.1 & 102.4 & 101.9 \\
\hline Range & $169-630$ & $161-689$ & $161-689$ \\
\hline Missing, $N(\%)$ & $50(36.5)$ & $81(30.1)$ & $131(32.3)$ \\
\hline
\end{tabular}

$144(35.5 \%)$ of $36-55$ letters, $162(39.9 \%)$ of 56-70 letters, and $46(11.3 \%)$ of $>70$ letters.

At baseline, 275/420 (67.7\%) eyes had OCT thickness data recorded on the EMR, and the mean central $1 \mathrm{~mm}$ retinal thickness OCT measurement was $353 \mu \mathrm{m}$ (SD \pm 102$)$. It was not routine practice to repeat OCT scans at months 1 and 2. For all other monthly assessment, time periods between 93.3 and $97.3 \%$ of eyes had OCT thickness data recorded on the EMR system.

\section{Clinic visits and the number of injections}

The mean number of clinic visits was 12.2 (range 7-14) in year 1 and 10.6 (range 4-13) in those completing followup in year 2. The mean number of injections administered in year 1 was 5.9 (range 3-13) with 122 $(30.5 \%)$ patients having an injection-free interval of 3 months and $76(18.8 \%)$ having an injection-free interval of 6 months at 1 year. The mean number of injections administered in year 2 was 3.6 (range 0-10) with 34 $(17.2 \%)$ patients having no injections in the second year of treatment. The mean proportion of eyes injected at each clinic visit after completion of the loading phase was $32.9 \%$ (range $28.4-36.6 \%$ ), and there was no difference between the baseline VA categories for the number of clinic visits or injections in years 1 or 2 (Table 2).

\section{Visual acuity}

At 1 year $366(90.1 \%)$ eyes had lost fewer than 15 letters, with $85(20.9 \%)$ gaining 15 or more letters, and at 2 years $172(86.7 \%)$ eyes had lost fewer than 15 letters, with 41 $(20.7 \%)$ gaining 15 or more ETDRS letters in the treated eye.

The mean VA score at 1 year was 58.5 letters (SD \pm 17.7$)$ and the mean change in VA was +4.1 letters $(S D \pm 14.2)$. At 2 years the mean VA score was 56.8 letters $(S D \pm 18.6$ ) and the mean change from baseline was +1.6 letters $(\mathrm{SD} \pm 17.6)$. At years 1 and 2 the range in the mean change from baseline was large (Figures 2 and 3).

At 1 year the mean VA change from baseline was +3.3 letters for eyes with minimally classic/occult CNV and was +5.8 letters for eyes with classic no occult/ predominantly classic CNV with mean actual acuities \pm SD of $58.6 \pm 17.3$ and $57.7 \pm 18.9$ letters, respectively.

At 2 years the mean VA change from baseline was -0.2 letters for eyes with minimally classic/occult CNV and +6.2 letters for those with classic no occult/ 
Table 2 Year 1 and 2 results by baseline VA categories

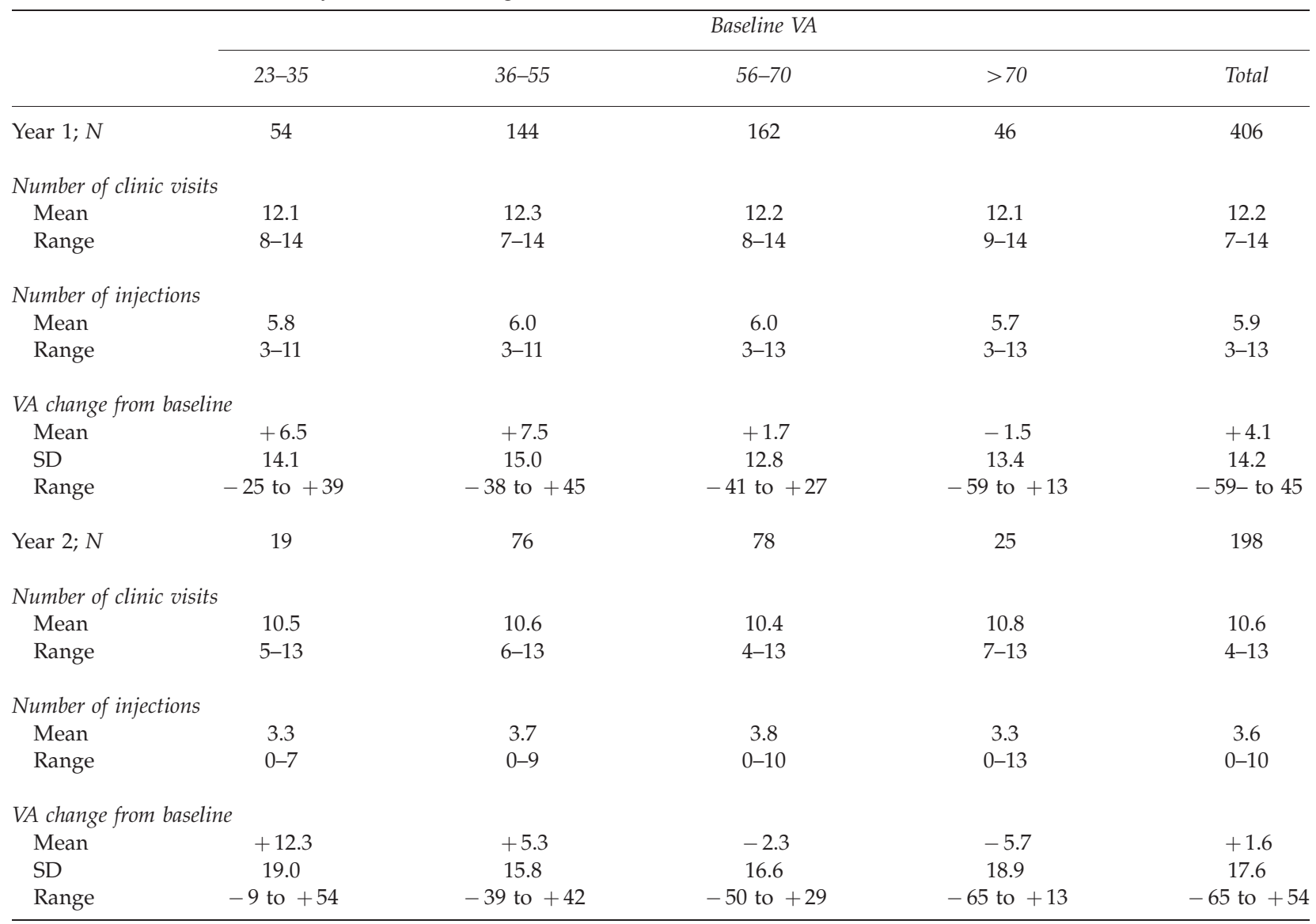

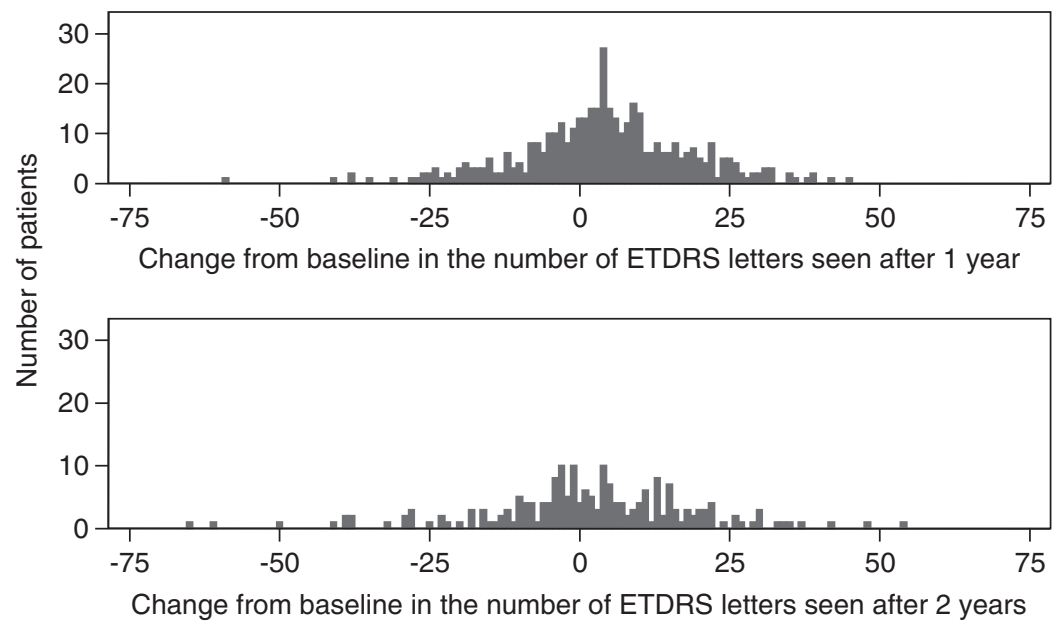

Figure 2 Change from baseline in the number of ETDRS letters seen after 1 and 2 years.

predominantly classic CNV, with mean actual acuities of 55.8 vs 59.4 ETDRS letters, respectively.

At 1 year those whose baseline VA was between 23-35, 36-55, and 56-70 ETDRS letters had a mean gain of +6.5 ,
+7.5 , and +1.7 letters, respectively, and those whose baseline VA was $>70$ letters had a mean loss of -1.5 letters. At 2 years those whose baseline VA was between 23-35 or 36-55 ETDRS letters had a mean gain of +12.3 


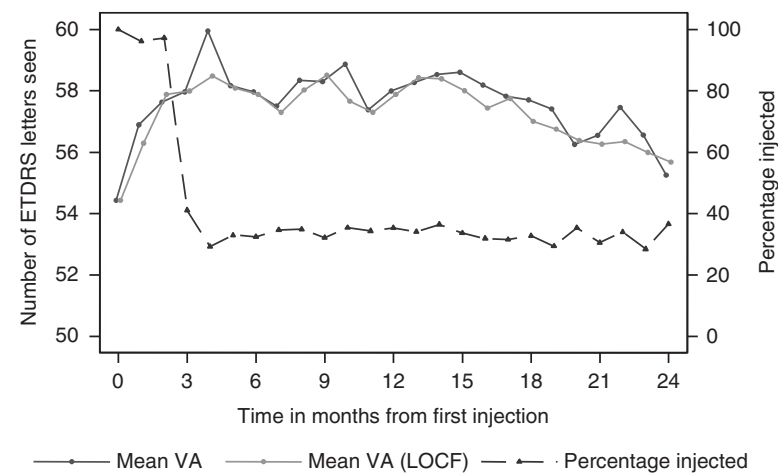

Figure 3 Mean VA with and without LOCF, and percentage of eyes injected at each month.

and +5.3 letters, respectively, and those whose baseline VA was $56-70$ or $>70$ letters had a mean loss of -2.3 and -5.7 letters, respectively (Table 2).

The MARINA and ANCHOR trials used the last observation carried forward (LOCF) missing data imputation method. When LOCF is applied to our cohort, the overall mean $( \pm$ SD) VA was 57.2 (1.0) EDTRS letters compared with 57.6 (1.2) EDTRS letters when LOCF was not used. The mean VA at each month was consistent if LOCF was or was not used (Figure 3).

\section{$V A$ from the end of the loading phase (1 month after the} third ranibizumab injection)

The mean changes in VA from end of the loading phase to year 1 and 2, respectively, were -2.9 and +0.9 letters for eyes in baseline VA category 23-35 ETDRS letters; +1.4 and -0.9 letters for baseline category $36-55$ letters; -0.4 and -3.2 letters for baseline category $56-70$ letters; and +0.6 and -2.8 letters for baseline category $>70$ ETDRS letters (Figure 4).

\section{OCT (Stratus, Cirrus HD, and Spectralis)}

At 1 year the mean central $1 \mathrm{~mm}$ OCT (Stratus, Cirrus HD (Zeiss, Dublin, CA, USA), Spectralis (Haag-Streit, Koeniz, Switzerland)) retinal thickness was $257.1 \mu \mathrm{m}$ $(\mathrm{SD} \pm 72.4)$ and the mean change in OCT from baseline was a $97.7-\mu \mathrm{m}$ decrease. At 2 years the mean OCT was $254.5 \mu \mathrm{m}(\mathrm{SD} \pm 70.5)$ and the mean change from baseline was a $78.3-\mu \mathrm{m}$ decrease. (Figure 5)

\section{Complications and cataract surgery}

In total, 3657 injections were administered to 406 eyes. There were two cases of endophthalmitis during the study period, a rate of 1 in every 1828 injections and of 1 in every 203 eyes. Cataract extractions were performed on five eyes after ranibizumab treatment commenced (all in the second year of treatment).

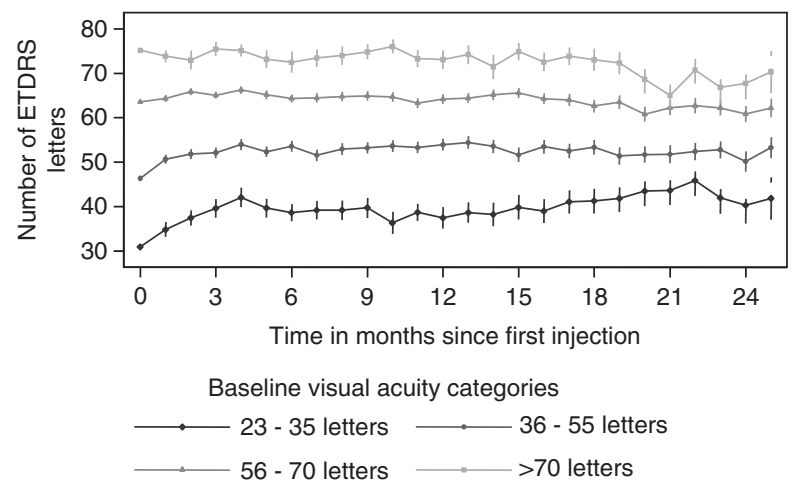

Figure 4 Mean VA at each month as per baseline VA category.

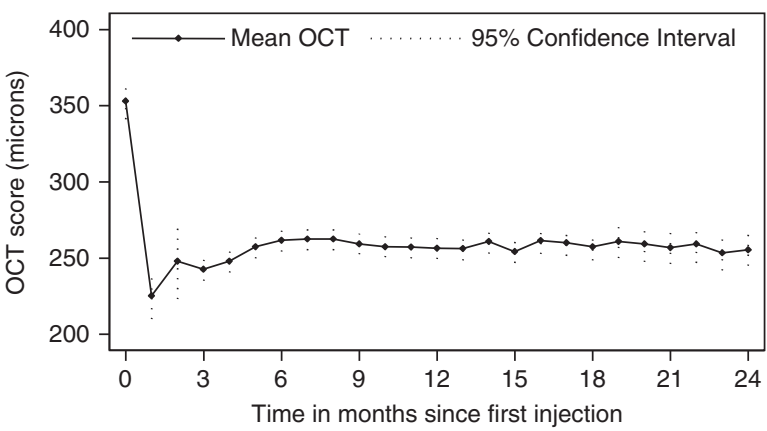

Figure 5 Mean central $1 \mathrm{~mm}$ OCT retinal thickness at each month.

\section{Discussion}

This paper presents one of the largest series of eyes with nAMD treated with ranibizumab in a routine clinical setting. The routine use of an EMR system has allowed close to clinical trial levels of data completeness as a byproduct of routine clinical care. Within the current literature, there is a paucity of 'real-world' data with regard to outcomes of ranibizumab treatment for nAMD, and previous reports are often on small cohorts of patients despite originating from major institutions. ${ }^{6-16}$

Few centres have emulated the mean VA gains of the ANCHOR and MARINA trials on unselected cohorts of patients. Table 3 compares the results in this study with that of the pivotal trials and pro re nata (PRN), and treat and extend reports demonstrating comparative mean VA at baseline and at 1 year.

Recently, a multicentre single-blind, non-inferiority trial compared intravitreal injections of ranibizumab with bevacizumab. Inclusion criteria included an age of 50 years or more, previously untreated active choroidal neovascularisation secondary to $\mathrm{NAMD}$, and VA between 80 letters (20/25) and 25 letters (20/320). This trial concluded that at 1 year bevacizumab and ranibizumab had equivalent effects on VA. Bevacizumab administered 


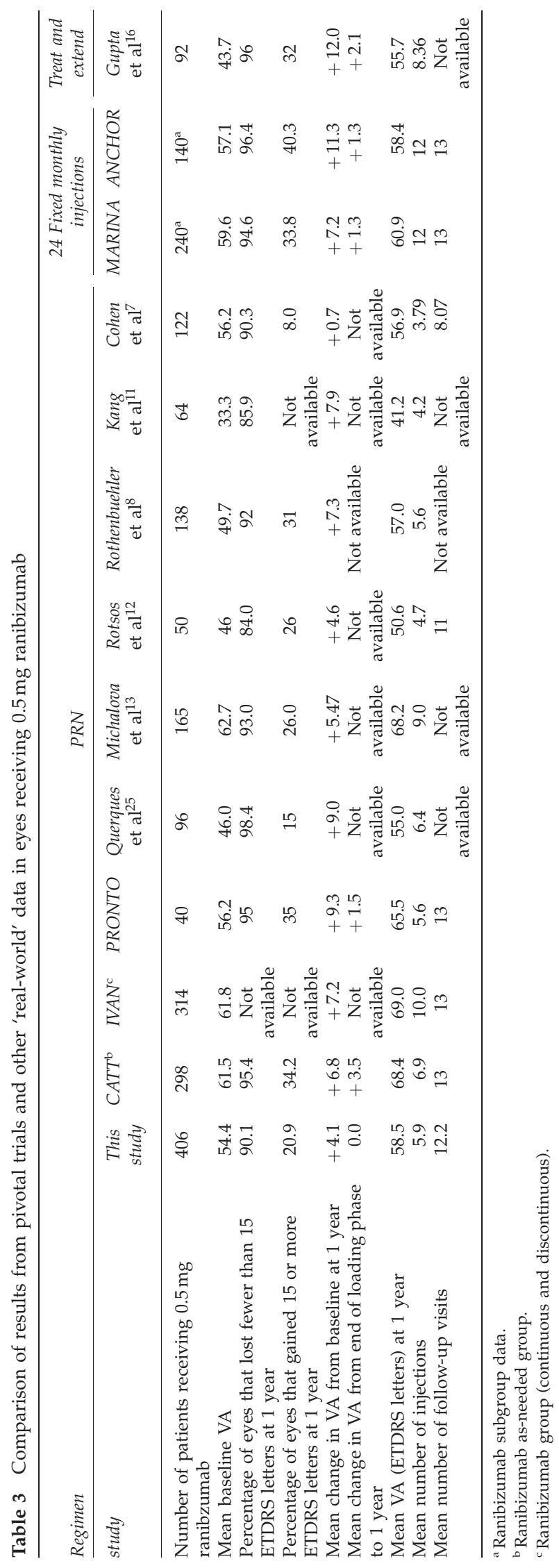

monthly was equivalent to ranibizumab administered monthly, with a mean of 8.0 and 8.5 letters gained, respectively. In addition, bevacizumab administered as needed was equivalent to ranibizumab as needed, with a mean of 5.9 and 6.8 letters gained, respectively. The mean number of injections in the ranibizumab as-needed group was $6.9 .{ }^{18}$ The baseline mean VA in the ranibizumab asneeded group was 61.5 ETDRS letters, which improved to 64.8 and 68.4 letters after the loading phase and at 1 year, respectively. At 2 years, ranibizumab and bevacizumab had similar effects on VA and treatment as needed resulted in less gain in VA, whether instituted at enrolment or after 1 year of monthly treatment. ${ }^{19}$

The IVAN trial is ongoing comparing the efficacy and safety of ranibizumab and bevacizumab intravitreal injections to treat nAMD at 2 years. Patients were randomised to four groups: ranibizumab or bevacizumab, given either every month (continuous) or as needed (discontinuous), with monthly review. The mean baseline and 1 year best-corrected VA in the ranibizumab group was 61.8 and 69.0 ETDRS letters, respectively. The comparison of VA at 1 year between bevacizumab and ranibizumab was inconclusive, but VAs with continuous and discontinuous treatment were equivalent. ${ }^{20}$

This study has demonstrated a mean VA at 1 year of 58.5 letters, which is comparable to the MARINA and ANCHOR trials of 60.9 and 58.4 letters, respectively, but lower than the PRN ranibizumab arms of the CATT trial and both ranibizumab arms of the IVAN study of 68.4 and 69, respectively. This study also demonstrates similar stability in acuity after the loading phase to the pivotal trials. The majority of the difference between our study and the clinical trials was a lack of improvement during the loading phase during which identical treatment was given. The possible explanations for the difference include a different case mix in routine clinical practice or the lack of repeat refractions between baseline and 1 year.

MARINA and ANCHOR demonstrated mean changes in VA from baseline to month 3 of +5.9 and +10.0 letters, respectively, and a mean change in VA from month 3 to 1 year of +1.3 letters in both trials. In our study the mean change in VA from baseline to the end of the loading phase was +4.1 letters and the mean change from the end of the loading phase to year 1 was 0.0 letters.

The case mix in this study was substantially different from clinical trials, as it included eyes with some structural damage at the fovea, so long as this was judged to be at least partially reversible; eyes with a long history of visual deterioration, and $11.3 \%$ of eyes had a baseline VA of $>70$ letters (Snellen equivalent of 6/12), all of which would have been excluded from the pivotal trials.

The proportion of eyes in each baseline VA category is also a major determinant of improvement in vision. Eyes 
in the 23-23, 36-55, 56-70, and > 70 ETDRS letter baseline groups gained $+9.4,+6.2,+2.1$, and -2.0 letters, respectively, at 1 year, and the mean change in VA from end of the loading phase to year 1 for each group were $-2.9,+1.4,-0.4$, and +0.6 letters, respectively, for each group. The majority of VA gains occurred at the end of the loading phase with little further gain or loss thereafter, and the greatest gains occurred in the groups with lower baseline VA. This is consistent with other studies in addition to ANCHOR and MARINA, which have demonstrated that baseline vision was the most important predictor of response to treatment. ${ }^{21,22}$

There is limited data on outcomes of eyes with baseline VA better than $>70$ letters (Snellen 6/12). In a recent study by Williams and Blyth, ${ }^{23}$ the eyes with baseline vision better than $6 / 12$ lost 0.5 letters at 1 year, similar to our result of -1.5 letters at 1 year for this subset of eyes. Other studies have described the ceiling effect that limits potential for improvement in eyes with good vision at baseline. $^{24}$

In conclusion, this study has demonstrated that in a routine clinical setting, gain in VA largely occurs during the loading phase of ranibizumab injections, but is of a lower magnitude than was achieved in the pivotal trials despite identical treatment. This is due to differences in case selection and the proportions of eyes in each baseline VA category. This suggests that reporting results of ranibizumab treatment in terms of mean change in VA from baseline at different time points is potentially misleading, and that better markers of the quality of a service are mean actual VAs at presentation, and annually thereafter, and stability of vision after the loading phase. Actual VA is the most important concern for patients and best reflects the quality of the whole care pathway of nAMD from referral to final follow-up.

\section{Summary}

\section{What was known before}

- The landmark randomised controlled clinical trials defined the gold standard for VA outcomes for selected patient populations with nAMD, that can be achieved with monthly injections for 24 months.

\section{What this study adds}

- In a routine clinical setting, gain in VA largely occurs during the loading phase of ranibizumab injections, but is of a lower magnitude than was achieved in the pivotal trials despite identical treatment. This is due to differences in case selection and the proportions of eyes in each baseline VA category.

- Mean change in VA is largely a function of selection criteria and baseline VA.

- The quality of a service is better judged by actual VA outcomes and maintenance of vision after the loading phase.

\section{Conflict of interest}

The authors declare no conflict of interest.

\section{References}

1 Bressler NM. Age-related macular degeneration is the leading cause of blindness. JAMA 2004; 291(15): 1900-1901.

2 Rosenfeld PJ, Brown DM, Heier JS, Boyer DS, Kaiser PK, Chung CY et al. Ranibizumab for neovascular age-related macular degeneration. $N$ Engl J Med 2006; 355(14): 1419-1431.

3 Brown DM, Kaiser PK, Michels M, Soubrane G, Heier JS, Kim RY et al. Ranibizumab versus verteporfin for neovascular age-related macular degeneration. $N$ Engl J Med 2006; 355(14): 1432-1444.

4 Brown DM, Michels M, Kaiser PK, Heier JS, Sy JP, Ianchulev $\mathrm{T}$. Ranibizumab versus verteporfin photodynamic therapy for neovascular age-related macular degeneration: two-year results of the ANCHOR study. Ophthalmology 2009; 116(1): 57-65; e55-57-65.e55.

5 Fung AE, Lalwani GA, Rosenfeld PJ, Dubovy SR, Michels S, Feuer WJ et al. An optical coherence tomography-guided, variable dosing regimen with intravitreal ranibizumab (Lucentis) for neovascular age-related macular degeneration. Am J Ophthalmol 2007; 143(4): 566-583.

6 Oubraham H, Cohen SY, Samimi S, Marotte D, Bouzaher I, Bonicel $\mathrm{P}$ et al. Inject and extend dosing versus dosing as needed: a comparative retrospective study of ranibizumab in exudative age-related macular degeneration. Retina (Philadelphia, Pa) 2011; 31(1): 26-30.

7 Cohen SY, Dubois L, Tadayoni R, Fajnkuchen F, NghiemBuffet S, Delahaye-Mazza C et al. Results of one-year's treatment with ranibizumab for exudative age-related macular degeneration in a clinical setting. Am J Ophthalmol 2009; 148(3): 409-413.

8 Rothenbuehler SP, Waeber D, Brinkmann CK, Wolf S, WolfSchnurrbusch UEK. Effects of ranibizumab in patients with subfoveal choroidal neovascularization attributable to agerelated macular degeneration. Am J Ophthalmol 2009; 147(5): 831-837.

9 Bandukwala T, Muni RH, Schwartz C, Eng KT, Kertes PJ. Effectiveness of intravitreal ranibizumab for the treatment of neovascular age-related macular degeneration in a Canadian retina practice: a retrospective review. Can J Ophthalmol 2010; 45(6): 590-595.

10 Kumar A, Sahni JN, Stangos AN, Campa C, Harding SP. Effectiveness of ranibizumab for neovascular age-related macular degeneration using clinician-determined retreatment strategy. Br J Ophthalmol 2011; 95(4): 530-533.

11 Kang S, Roh Y-J. One-year results of intravitreal ranibizumab for neovascular age-related macular degeneration and clinical responses of various subgroups. Jpn J Ophthalmol 2009; 53(4): 389-395.

12 Rotsos T, Patel PJ, Chen FK, Tufail A. Initial clinical experience of ranibizumab therapy for neovascular agerelated macular degeneration. Clin Ophthalmol (Auckland, NZ) 2010; 4: 1271-1275.

13 Michalova K, Wickremasinghe SS, Tan TH, Chang A, Harper CA, Downie JA et al. Ranibizumab treatment for neovascular age-related macular degeneration: from randomized trials to clinical practice. Eye (London, England) 2009; 23(8): 1633-1640. 
14 Dadgostar H, Ventura AACM, Chung JY, Sharma S, Kaiser PK. Evaluation of injection frequency and visual acuity outcomes for ranibizumab monotherapy in exudative agerelated macular degeneration. Ophthalmology 2009; 116(9): 1740-1747.

15 Arias L, Roman I, Masuet-Aumatell C, Rubio MJ, Caminal $\mathrm{JM}$, Catala J et al. One-year results of a flexible regimen with ranibizumab therapy in macular degeneration: relationship with the number of injections. Retina (Philadelphia, $P a$ ) 2011; 31(7): 1261-1267.

16 Gupta OP, Shienbaum G, Patel AH, Fecarotta C, Kaiser RS, Regillo CD. A treat and extend regimen using ranibizumab for neovascular age-related macular degeneration clinical and economic impact. Ophthalmology 2010; 117(11): 2134-2140

17 StataCorp. Stata Statistical Software: Release 11. StataCorp: College Station, TSL, 2009.

18 Martin DF, Maguire MG, Ying G-s, Grunwald JE, Fine SL, Jaffe GJ. Ranibizumab and bevacizumab for neovascular age-related macular degeneration. N Engl J Med 2011; 364(20): 1897-1908.

19 Martin DF, Maguire MG, Fine SL, Ying GS, Jaffe GJ, Grunwald JE et al. Ranibizumab and bevacizumab for treatment of neovascular age-related macular degeneration: two-year results. Ophthalmology 2012; 119(7): 1388-1398.

20 Chakravarthy U, Harding SP, Rogers CA, Downes SM, Lotery AJ, Wordsworth $\mathrm{S}$ et al. Ranibizumab versus bevacizumab to treat neovascular age-related macular degeneration: one-year findings from the IVAN randomized trial. Ophthalmology 2012; 119(7): 1399-1411.

21 Boyer DS, Antoszyk AN, Awh CC, Bhisitkul RB, Shapiro H, Acharya NR. Subgroup analysis of the MARINA study of ranibizumab in neovascular age-related macular degeneration. Ophthalmology 2007; 114(2): 246-252.

22 Kaiser PK, Brown DM, Zhang K, Hudson HL, Holz FG, Shapiro $\mathrm{H}$ et al. Ranibizumab for predominantly classic neovascular age-related macular degeneration: subgroup analysis of first-year ANCHOR results. Am J Ophthalmol 2007; 144(6): 850-857.

23 Williams TA, Blyth CP. Outcome of ranibizumab treatment in neovascular age related macula degeneration in eyes with baseline visual acuity better than 6/12. Eye (London, England) 2011; 25(12): 1617-1621.

24 Shona O, Gupta B, Vemala R, Sivaprasad S. Visual acuity outcomes in ranibizumab-treated neovascular age-related macular degeneration; stratified by baseline vision. Clin Exper Ophthalmol 2011; 39(1): 5-8.

25 Querques G, Azrya S, Martinelli D, Berboucha E, Feldman A, Pece A et al. Ranibizumab for exudative age-related macular degeneration: 24-month outcomes from a single-centre institutional setting. Br J Ophthalmol 2010; 94(3): 292-296. 